\title{
THE GEOMATICS CONTRIBUTION FOR THE VALORISATION PROJECT IN THE ROCCA OF SAN SILVESTRO LANDSCAPE SITE.
}

\author{
D. Brocchini ${ }^{\mathrm{a}}$, F. Chiabrando ${ }^{\mathrm{b}}$, E. Colucci ${ }^{\mathrm{b}}$, G. Sammartano ${ }^{\mathrm{b}}$, A. Spanò $\grave{\mathrm{b}}^{\mathrm{b}}$ L. Teppati Losè ${ }^{\mathrm{b} *}$, A. Villa ${ }^{\mathrm{b}}$.

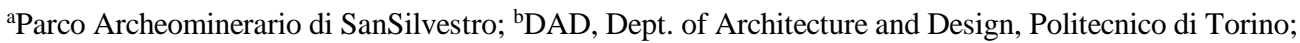

Commission WG V/1, WG V/2, WG II/8 WG IV/2

KEY WORDS: Multi-sensor 3D survey, 3D modelling, Multi-stratified site, Landscape Heritage, WEB GIS, Cultural Mining Field.

\begin{abstract}
:
This paper proposes an emblematic project where several multi-sensor strategies for spatial data acquisition and management, range based and image based, were combined to create a series of integrated territorial and architectural scale products characterized by a rich multi-content nature. The work presented here was finalized in a test site that is composed by an ensemble of diversified cultural deposits; the objects that were surveyed and modelled range from the landscape with its widespread mining sites, the main tower with its defensive role, the urban configuration of the settlement, the building systems and techniques, a medieval mine. For this reason, the Rocca of San Silvestro represented a perfect test case, due to its complex and multi-stratified character. This archaeological site is a medieval fortified village near the municipality of Campiglia Marittima (LI), Italy. The Rocca is part of an Archaeological Mines Park and is included in the Parchi della Val di Cornia (a system of archaeological parks, natural parks and museums in the south-west of Tuscany). The fundamental role of a deep knowledge about a cultural artefact before the planning of a restoration and valorisation project is globally recognized; the qualitative and quantitative knowledge provided by geomatics techniques is part of this process. The paper will present the different techniques that were used, the products that were obtained and will focus on some mapping and WEB GIS applications and analyses that were performed and considerations that were made.
\end{abstract}

\section{INTRODUCTION}

Given that the whole management of the archaeological Mines Park of Valle di Cornia welcomed just over a year ago with extreme interest and favoured the hypothesis that the site of San Silvestro could be objective for carrying out research and training activities in the field of innovative technologies of Geomatics, this introduction might arise from a question. How is possible that one of the archaeological sites most investigated by the relative scientific community, which has been an important research field for generations of young students in Archaeology, as well as a rich source of inexhaustible research and studies for an extensive research group and has being studied and documented over the last 3 decades, still need to be surveyed and documented?

The answer is in fact underlain at least since the last two decades of research on the documentation of landscape and cultural heritage, in its varied and interdisciplinary forms, including obviously those related to the evolution of the production of spatial information and the ways of its collection, processing archiving representation and communication for the different and stratified stakeholders in Cultural Heritage $(\mathrm{CH})$ conservation and for the public.

To provide a schematic reference at least of the most relevant and current issues that answer the previous question:

- It has been established since many years that the $\mathrm{CH}$ documentation has to be continuous, that it should go with everystage of life of the heritage and that it has to be foreseen for future applications. (Such principles are contained in ICOMOS charters, particularly in Sofia Charter, 1996, re-affirmed by European Landscape Convention of the Council of Europe, 2000)

- The methods of spatial information production have been invested by an extraordinary technological innovation. New techniques, instruments and methodologies were developed thanks to the digital revolution. (on top of others for $\mathrm{CH}$ documentation: LiDAR technology and digital Photogrammetry integrated with image matching and Structure from Motion (SfM) algorithms, derived from the Computer Vision field. (for example (Kersten, Lindstaedt 2012)

- Not the same as with the archiving and sharing systems so much that today there is an extreme need to develop these latter to be able to make the most effective and usable product innovations. A research direction that is added to GIS studies is the one that investigates Historical Building Information Modelling (HBIM) systems. (Murphy et al.,2012; Sammartano et al. 2016)

- Developments in computing and artificial intelligence have created new requirements for digital storage of information and documentation. Semantic interoperability is key to managing and sharing information. Both interoperability between databases, sharing and reuse of data and schemes, and the recovery of information from large archives, plus the possibility of automatic reasoning, are favoured by the imposition of constraints on the interpretation of data through use of domain ontologies as a reference for modelling data in information systems. (Noardo, 2016)

The development of digital inventories imposes the use of standards and the need for sharing between different fields of use since the asset scenario is largely interdisciplinary. There are

\footnotetext{
* Corresponding author
} 
several standards in the geographic field and in the $\mathrm{CH}$ field. However, the former includes limited representation scales (1: 100, OGC CityGML) and the semantic values considered are not suitable. Seconds (in particular CIDOC-CRM ontology) arise for documentation of museum objects. In recent years, many studies are developing integration. (Ronzino et al., 2015; Costamagna, Spanò, 2013)

\subsection{Contribution of Geomatics to the landscape valorisation}

The purpose of the cooperation and the contributions from Geomatics systems applications in landscape valorisation of Rocca San Silvestro site can only fit into the strategies that have already been proven particularly effective in the last years. The aim is to stimulate the tourist vocation of the area, in line with global and local norms in the cultural field that pursue the knowledge, understanding and enjoyment of the archaeological heritage of the regional territory through the study, collection and documentation of the history and traces in the Archaeological Mines Park of San Silvestro, (LI), Italy. (Semplici et al. 2011)

One of the first goals is based on communication and knowledge of the territory, the past and the stories of the ancient finds need to be revealed, transmitted and understood through a visit that extends from the coast to the hinterland of Livorno.

The contribution reported in this paper aims firstly to conceive the organization of a Web-GIS system as an option capable of at the same time ensuring the knowledge, enjoyment and protection of this heritage where roots are found not only in the mining area of the metallic hills, but of all the Tuscan culture. (Colucci 2017) Then fieldwork applying integrated methods of 3D survey and high scale modelling will follow.

\subsection{The Team DIRECT experience}

A central role for the protection of heritage should be, and actually is, played by the institutions that are responsible for the formation of the new generation of cultural operators. University, association, schools, etc...should put any possible efforts in the formation of prepared operators with a deep sensitive for the different types of heritage. The DIRECT project (DIsaster RECovery Team) was founded in 2013 also with these aims (Grasso, 2015). DIRECT is a team of the Politecnico of Turin, composed by students with different backgrounds (the team is composed by students from the areas of Architecture and Engineer), and is configured as a supplementary and voluntary activity. This initiative aims to contribute actively to the protection of the territory, of the architectural heritage and environmental, architectural and archaeological assets, during environmental emergencies or in the case of goods subjected to dangers of even an ordinary, continuous type. Every year the team involves the students in training activity, both with frontal lessons and stages in the field. In the summer of 2016, thanks to an institutional agreement between the Politecnico di Torino and the Parchi della Val di Cornia, the stage was realised at Rocca of San Silvestro (LI), Tuscany.

\subsection{The Rocca of San Silvestro}

The fortified village of Rocca of San Silvestro (Fig. 1) was founded in the tenth century A.D. and is now part of the municipality of Campiglia Marittima (LI), Italy. Starting from the 1996 the Rocca became part of an Archaeological Mines Park (Guideri, 2008) and was included in the Parchi della Val di
Cornia (a system of archaeological parks, natural parks and museums in the south-west of Tuscany).

The archaeological site is included in a rich and complex territory and was tightly tied with the mining activity. The Rocca of San Silvestro was founded to be a stronghold to control the mineral resources and monitor their extraction. A stone tower represented the central point of the settlement and all the other structures were built around it during the centuries. The twelfth century represented for San Silvestro, as for many other castles in the region, the period of maximum splendour: the village was encompassed by massive defensive walls that included several houses for the miners, a church dedicated to S. Silvestro, a cemetery and different other structures (bread oven, ceramic kiln, forge, oil mill, etc..). Starting from the 1984 the site was excavated and studied by the late Professor Riccardo Francovich and his team (Bianchi, 1997; Francovich \& Parenti, 1987; Francovich \& Wickham, 1994). The site presented well conserved structures of the medieval period (Bianchi, 1996; Semplici, 2011), that are still standing for a considerable height.

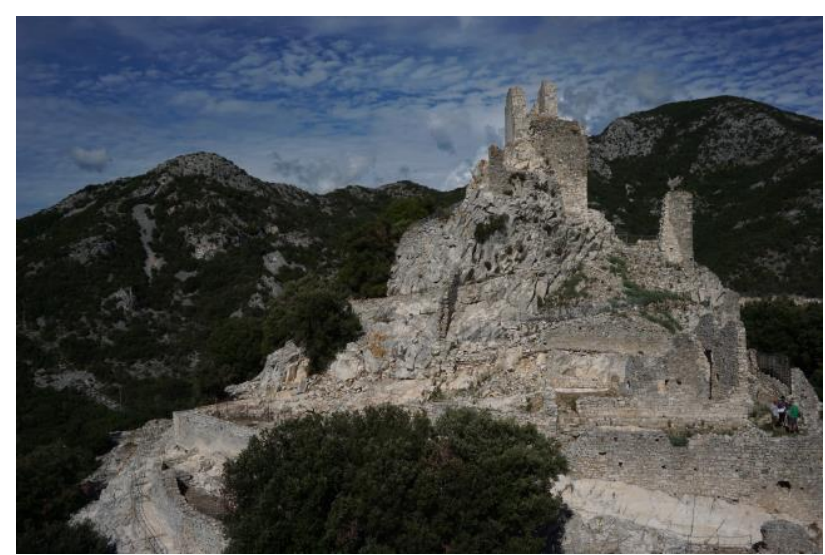

Figure 1. Image from UAV of the Rocca of San Silvestro, Sept. 2016

\section{LANDSCAPE ANALYSES BY GIS}

The valorisation of the landscape of the metallic hills of the Archaeominerary Park was able to exploit favourable conditions provided by the availability of the integration of Piano Territoriale "with specific consideration of the landscape values" (Regione Toscana, 2015) according to the Code of Cultural Heritage. The formulation of a specific GIS platform for the park that has been built, obviously comes from the regional framework and intends to harmonize with it.

The dataset available were the following:

- The regional open data. (the medium scale regional map, including topographical dataset, DTM, Orthophoto, PIT datasets, ISTAT data, etc.)

- The archaeological dataset collected by the Parchi della Val di Cornia

- The orthophoto and Digital surface models derived from fieldwork described in following paragraph.

An open source solution, based on QuantumGIS software, has been developed and implemented. After the harmonization of the different dataset, converting the data in the standard reference system (UTM-WGS84), several territorial analyses were performed. The main analyses carried out were:

- territorial analyses for the identification of historical landmarks, park's museums and paths (Figure 3);

- the spatial and chronological distribution of the different archaeological evidences and mining sites; 
- the geomorphological conformation of the territory around the site;

- the land use transformation within the park boundaries;

- 3D analyses using the DSM and the ortho-photo acquired during the on-site work.

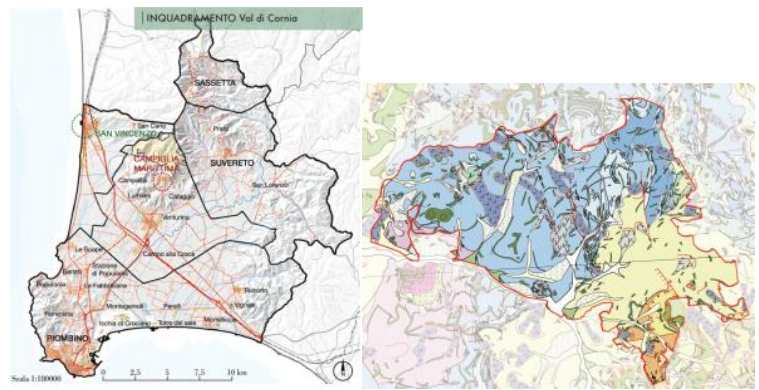

Figure 2. (left) The general framework map of the area, (right) the geological Continuum Map

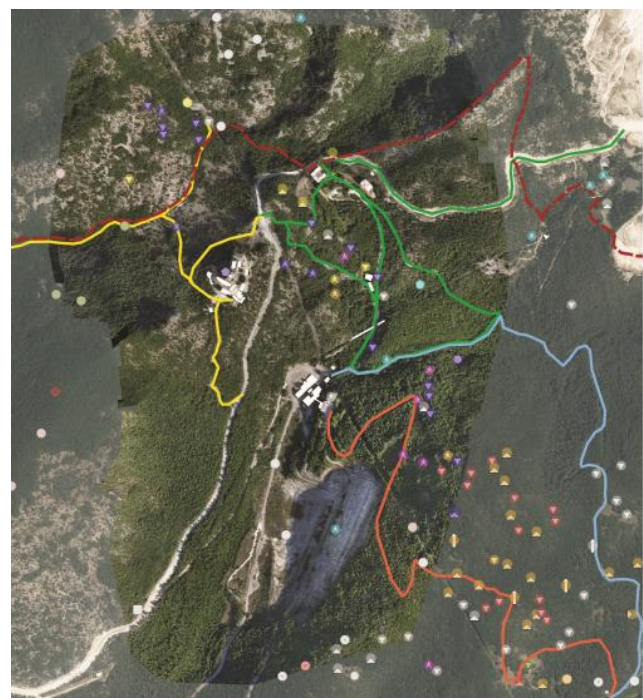

Figure 3. Orthophoto realized by the eBee platform and regional orthophoto of GEOscopio, individuation of the paths and the mining sites in the area.

\subsection{The Web GIS platform}

The Park WebGIS, according to the principles now customary for this kind of project, was born as a tool for working, managing and organizing the data of the San Silvestro Park and communicating these to users who will be able to see the updates of the studies taking place in the area, for example, by selecting separate and targeted views. The client-server structure use an Open-Source platform which lets the client to access to the geographic information in the web, being the Rocca of San Silvestro WebGIS designed limited to the boundaries of the Park. The architecture platform allows to access to every dataset in a transparent, immediate and effective way. There is, however, a stratification of users and the ability to manipulate the data is managed with different levels of access.

From a more technical point of view, first of all the DB was created using PostgreSQL, an Open-Source software for the databases management (SQL language). Postgres is the ORDBMS, Object Relational Database Management System. Its graphic interface is PgAdmin. In Postgres DB's entities were created, while the geometry was defined using the plug-in of QuantumGIS, PostGIS.
The definition and publishing of the DB in the Web Site is managed by GeoSErver, which is a OGC compliant implementation of a number of open standards such as Web Feature Service (WFS), Web Map Service (WMS), and Web Coverage Service (WCS).

The WebGIS Map can be visualized with OpenLayers (Figure 4), a Java Script library with the features of the entities, or downloading the .KML file extension in Google Earth (Figure 5).

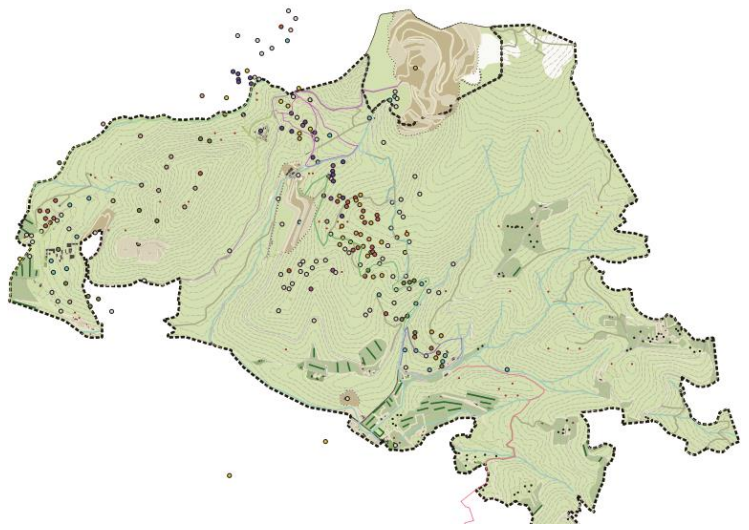

Figure 4. OpenLayer view of the published Web GIS

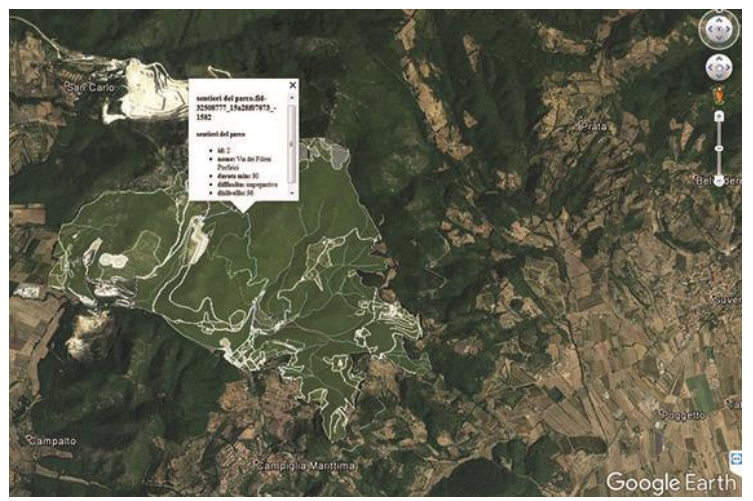

Figure 5. Google Earth view of the Web GIS

\section{FIELDWORK}

As is clear from the historical framework described above the Rocca of San Silvestro and its territory are configured as a complex and multi-stratified site. For this reason, we needed to carefully project the acquisitions of data and the fieldwork. We decided to perform a multi-sensors and multi-scale survey and to employ different techniques in the five days of work on the site. The first steps, preliminary to all the acquisitions, have been the design and measurement of the topographic network planned to georeference together all the different sets of data. We materialized on the ground 11 vertices (Figure 6) that were measured with GNSS techniques and Total Station. The GNSS acquisition lasted almost 30 minutes for each vertex and in a second phase the network was calculated using the national network of permanent stations.

To perform a complete and multi-scale survey of the Rocca different sensors and techniques were employed: UAVs (both fixed wing and multi rotors), TLS (Terrestrial Laser Scanner), SLAM techniques (Simultaneous Localizations And Mapping) and CRP (Close Range Photogrammetry) were used.

\subsection{UAVs acquisitions}

The first acquisitions performed to fulfil the multi-scale purpose of the survey were the UAVs flights. To achieve a complete 
documentation of the territory in which the Rocca is inserted we follow two acquisition strategy using different platforms. The first flights were realized using a fixed wing platform: the eBee by Sensfly (commercialized by MenciSoftware in Italy). Moreover, in order to enhance the scale and of the surveyed areas with the objective of documenting with an high level of detail the structures of the castle, five flights with a multi-rotors UAV were realised using traditional nadir images and oblique one as well.

\subsubsection{Fixed wing}

Two flights were performed with the eBee drone (Figure 7. left) to cover a wide area around the Rocca of San Silvestro. The two flights were planned using the eMotion software and realized to have the following main characteristics:

\begin{tabular}{|l|l|}
\hline Flight height & $\approx 100 \mathrm{~m}$ \\
\hline Total $\mathrm{n}^{\circ}$ of images (2 flights) & 458 \\
\hline Area covered & $1.1106 \mathrm{~km}^{2}$ \\
\hline Camera & Canon PowerShot S110 \\
\hline Image dimension & $4000 \times 3000$ pixels \\
\hline Sensor dimension & $7,44 \times 5,58 \mathrm{~mm}$ \\
\hline GSD (Ground Sampling Distance) & $6,1 \mathrm{~cm}$ \\
\hline
\end{tabular}

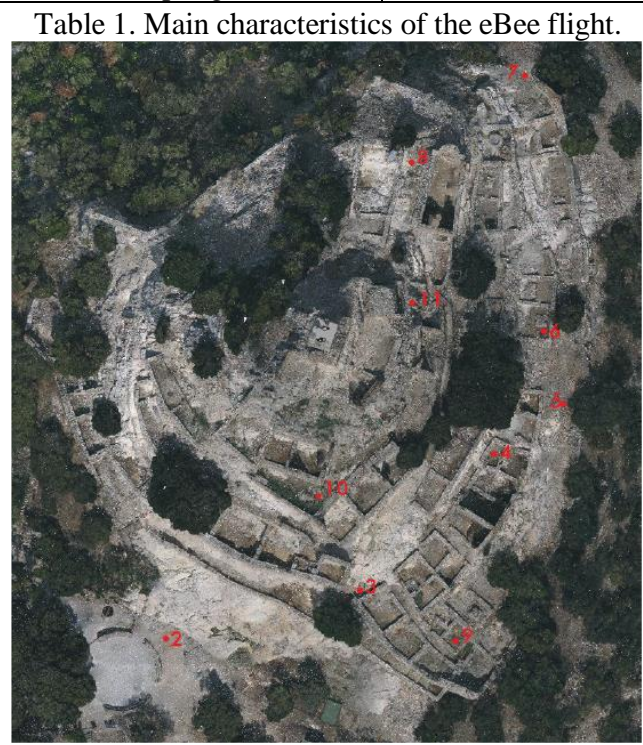

Figure 6. The eleven vertices of the topographic network superimposed to the orthophoto generated from low altitude drone flights.

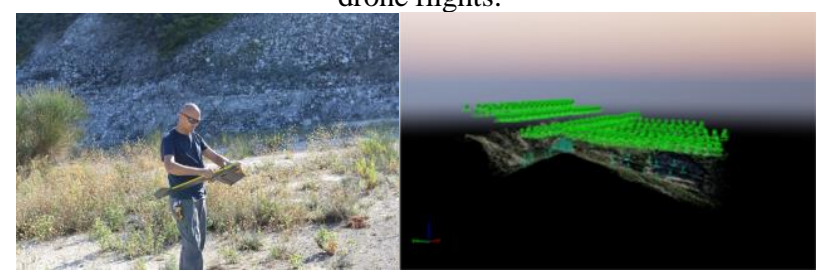

Figure 7. The eBee during the take-off (left) and the acquisition scheme of the images (right)

\subsubsection{Multi-rotors}

The higher details 3D models of the Rocca were achieved performing five flights, using the multi-rotors platform UBIK DIATI MK01 (Fig 8):

\begin{tabular}{|l|l|}
\hline Flight height & $\approx 40 \mathrm{~m}$ \\
\hline Total $\mathrm{n}^{\circ}$ of images $(5$ flights) & 1119 \\
\hline
\end{tabular}

\begin{tabular}{|l|l|}
\hline Area covered & $0,2500 \mathrm{~km}^{2}$ \\
\hline Camera & Sony Alpha 5100 \\
\hline Image dimension & $6000 \times 4000$ pixels \\
\hline Sensor dimension & $23,5 \times 15,6 \mathrm{~mm}$ \\
\hline GSD (Ground Sampling Distance) & $1,28 \mathrm{~cm}$ \\
\hline
\end{tabular}

Table 2. Main characteristics of the multi-rotors flight

The flights were planned to ensure a large overlap between the different images ( $>80 \%$ along strips, $>70 \%$ across strips). The employed software for set-up the flights was Mission Planner, created by Michael Oborne, that connects the platform to the ground station. The flights were planned and executed with the following modalities:

1. Nadiral configuration of the camera. Flight lines direction North-South and West-Est.

2. Oblique configuration of the camera $\left(\approx 45^{\circ}\right)$. Flight lines direction North-South, West-Est and circular (with the centre of the circle in the middle of the site).

A detailed report on the planning and data processing steps is described in Chiabrando et al., 2017.
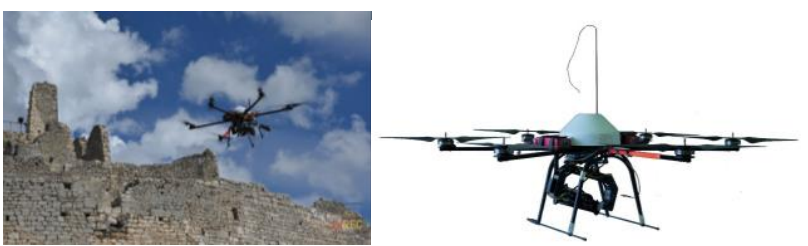

Figure 8. The UBIK DIATI MK01flying on the Rocca.

\subsection{Terrestrial Laser Scanner}

The acquisitions with the TLS have been focused on the east part of the village, which coincide with the residential area of the settlement. This densely built area needed particular detailed 3D survey and models as in the future it would be the subject of consolidation and restoration works, lying on a slope of the hill subject to landslides. A Faro Focus 3D (X 130) by Cam2 has been used: 80 scans were acquired in the position showed in figure 9 , and the following parameters were used:

\begin{tabular}{|l|c|}
\hline $\mathrm{N}^{\circ}$ of acquisitions & 80 \\
\hline $\mathrm{N}^{\circ}$ of registered acquisition & 80 \\
\hline Medium $\mathrm{n}^{\circ}$ points/scans & $20^{*} 10^{5}$ \\
\hline Resolution (MPti) & $1 / 4(1 \mathrm{pt} / 6 \mathrm{~mm}$ at $10 \mathrm{~m})$ \\
\hline Quality & $4 \mathrm{X}$ \\
\hline Scan area & $360^{\circ}$ \\
\hline
\end{tabular}

Table 3. Scans parameters

\subsection{Close range photogrammetry}

To complete and integrate the TLS survey several photogrammetric acquisitions (Fig. 10) were also performed in the residential area of the site. The acquisitions have been organized and planned considering the configuration of the remains of the dwelling which has masonry at different heights and degree of conservation. Two different Digital single-lens reflex (DSLR) cameras were employed: Nikon D800E (CMOS 35,9 x 24,0 mm, image size 7360 x 4912 px) and Canon EOS 5D Mark II (CMOS 36 x 24 mm, image size 5616 x 3744 px) Those images were acquired in the areas where the archaeological evidences are more conserved such as the church of San Silvestro (Figure 10), which make CRP collections effective. 


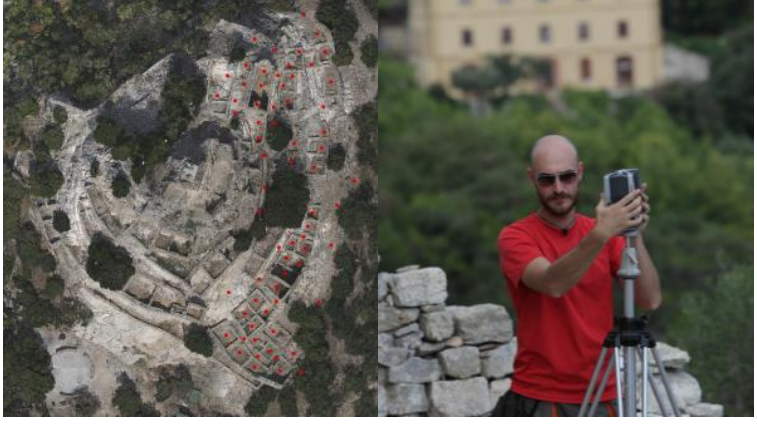

Figure 9. TLS acquisitions (right) and scans position (left)
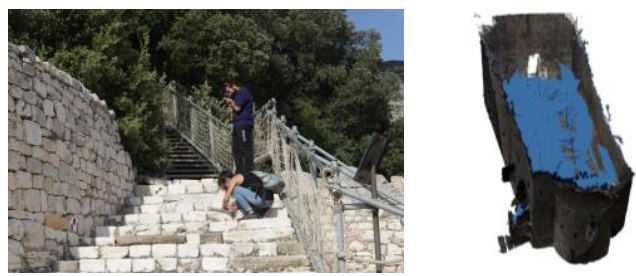

Figure 10. CRP acquisition phases (left) and example of the processed data (right)

\subsection{Slam techniques}

The opportunity to be able to work on a surprisingly interesting site, which requires different points of view and different approaches in the description of its components, always recommends us the use of various methods and techniques, even experimenting those particularly innovative to test the integration with the most consolidated ones. The stage at Rocca San Silvestro was a great opportunity to test a new solution for the rapid mapping, working both indoor and outdoor and offering lower resolution cloud models compared to TLS: that was the SLAM techniques. The hand-held Zeb REVO by GeoSlam was the system we had the chance to test (Figure 11), thanks to the cooperation with ME.S.A srl. Two different acquisitions were completed: one walked through the entire visit path of the fortress, starting from the entrance to the east, following exactly the ancient ascent to the culminating part of the fortified village and rearing from the other side according to the ancient road that embraces the cone shaped Rocca. The second data collection and modelling has been achieved at the Buca della Faina, an historical mine $1 \mathrm{~km}$ southeast from the castle, that the management of the Val Cornia Park would like to make accessible to the public.

This device consists in a 2D lightweight time-of-flight scanner with $30 \mathrm{~m}$ maximum range (Hokuyo scanner) and an Inertial Measurement Unit (IMU), which ensure roughly the position during the motion capturing. SLAM technology, schematically, exploits the geometric features and constrains present in the surveyed environment, correcting the acquisition trajectory, and based on these positions, operates a cloud-to-cloud alignment to generate the overall cloud. (some results in paragraph 5.2).
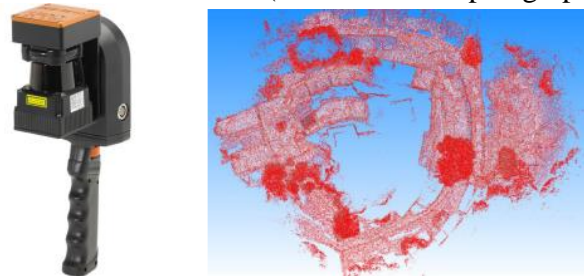

Figure 11. The Zeb Revo by GeoSlam (left) and a plan view othe the dataset acquired on the Rocca (right)

\section{DATA PROCESSING}

For the processing, analyses and management of the data collected on the field we decided to test both open-source and commercial solutions. For the processing of all the different sets of data, with the aim to obtain a common reference system and to check the accuracy of the achieved products several Ground Control Points (GCPs) and CPs (Check Points) have been used in the photogrammetric and LiDAR process as well. The points were surveyed using GNSS (Global Navigation Satellite Systems) in RTK (Real Time Kinematic) mode or using tradition side shot approach using a reflector less Total Station. As GCPs or CPs, some artificial markers have been positioned on the terrain or on the archaeological remains before the flights and the scans acquisition.

\subsection{Aerial Photogrammetry}

The data collected from the aerial platforms were processed using two software: Pix4D mapper Pro and ContextCapture (Bentley Systems). The data collected from the eBee platform allowed to generate point cloud, DEM and orthophoto that provide a general overview of the territory around the site (Figure 8). As mentioned earlier, the processing of the multi-rotors flights was more complex. First of all the influence of different parameters in the photogrammetric process has been analysed and tested (Chiabrando, et al. 2017), furthermore starting from those results a SfM approach combining nadir images and oblique has been fulfilled in order to obtain products able to better document the ancient structures especially in the elevated parts. For this purpose, ContextCapture by Bentley was used (Figure 12) providing firstly a higher resolution and scale orthophoto of the Rocca (compared with the Ebee results), secondly a complete 3D textured model of the settlements, and finally an enhanced texture aimed to complete the LiDAR model.

\section{2 $\quad$ TLS processing}

The scans acquired on the field were processed using the software Faro Scene. Since the number of scans was very high, splitting the process in different projects has been necessary. We worked with 15 projects that were realised considering the positions of the scans in relation to the type of buildings aggregation. For each project, the typical LiDAR data processing workflow has been fulfilled: point cloud filtering, colouring, registration and georeferencing. After exporting the interoperable files (*.e57), the huge point model (Figure 13) was triangulated and several two and three-dimensional representations satisfying the needs of the built heritage properly readings by potential stakeholders of the project were extracted and further elaborated. The DSLR cameras images processed with a Structure from Motion (SfM) approach have been used to enhance the texture of the models derived from the TLS.

\subsection{SLAM processing}

The ZebRevo collected clouds have been pre-processed using the interesting GeoSLAM Pay-as-you-go on-line method, which avoids users to face the cost of software but to have processed clouds at a really interesting cost, for example having hired the capture device. The result consisted in models of 33 million points for the Rocca and in 42 million points for the Buca della Faina. 

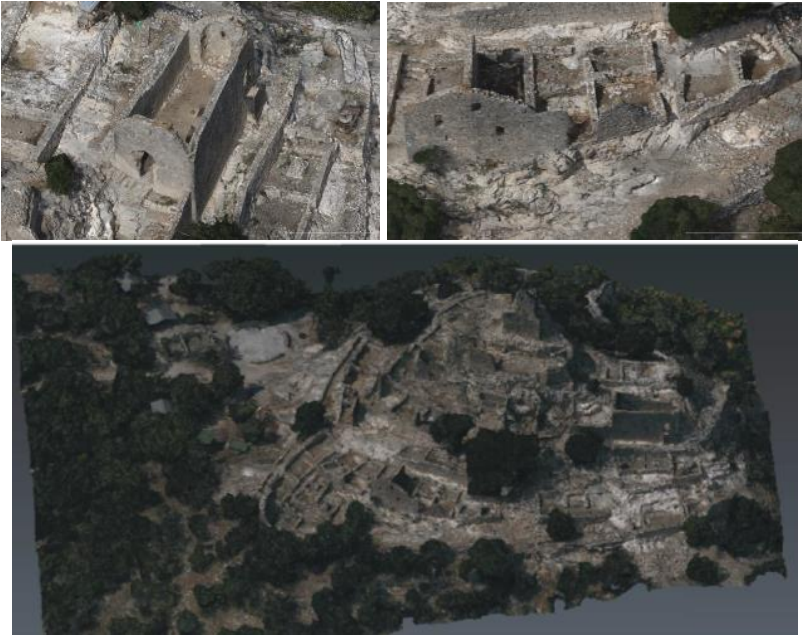

Figure 12 (Above) Close up views of San Silvestro 3D aerial model, (below) a general bird eye view of the complete 3D model.

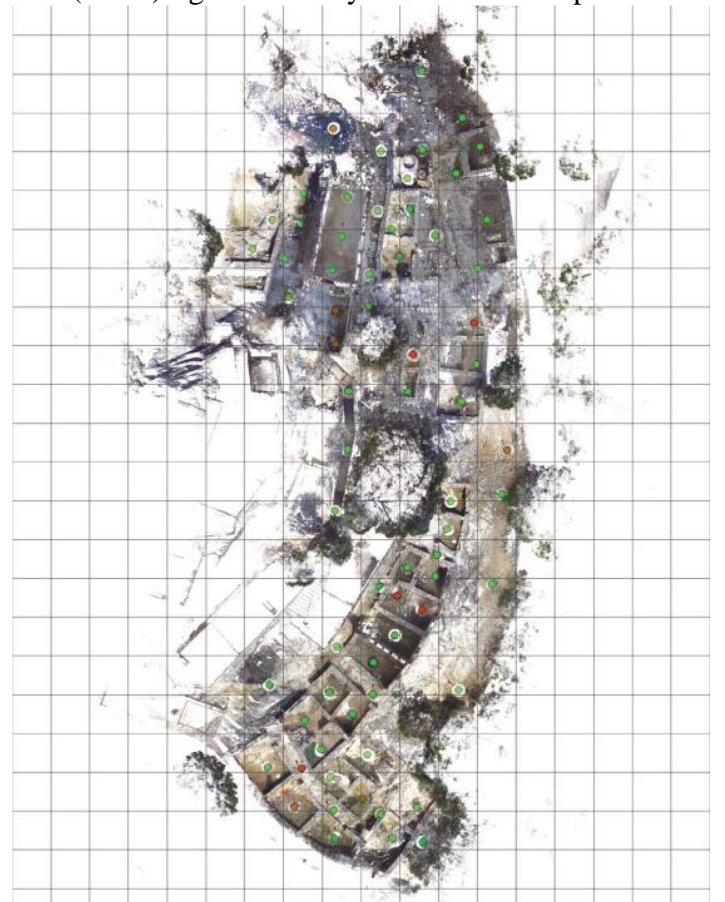

Figure 13. Plan view of the registered scans pertaining the residential district of the Rocca di San Silvestro (PointCab software) (Villa, 2017)

Considering that the real extension of the Rocca point clouds, in terms of meters walked, is extremely higher than that of the mining tunnel, it is interesting to observe the following consideration. The mine was scanned with the help of professional speleologists: much of the mine can be visited by on all fours or by adopting speleological downhill techniques. This certainly has greatly influenced the slowness of the acquisition and therefore the cloud density is far superior to the Rocca cloud, which has been walked by a regular step.

The crucial point of this technology is the control of the trajectory during the movement, which is estimated and corrected thank to the $3 \mathrm{D}$ cloud acquired using a variation of traditional ICP (iterative closest point) scan-matching (Bosse, Zlot, 2009). The development of the system has taken advantage of the opportunity to help the correction by the execution of closed loop trajectories during the mapping path, which also leads to better assess the overall quality of the final 3D cloud. The marketed system guarantees an absolute accuracy of position variable between $3 \mathrm{~cm}$ (close path) and $40 \mathrm{~cm}$ depending on the type of environment mapped. (http://geoslam.com/)

After a point cloud processing according to the time (time data embedded in the 3D data), segmentation, post registration, georeferencing and optimization, the point cloud was ready to be analysed with other sensors results, with the lack of radiometric information (the actual Geoslam system do not collect RGB data integrated to the range data yet).

\section{USE OF THE PRODUCTS IN RESEARCH AND COMUNICATION PROJECTS}

We will focus on two specific experiences on the use of the products derived from multi-sensors survey and 3D modelling with the aim of highlighting two different types of results use. The first study is devoted to the possible use of the LiDAR models integrated by the contribution of the UAV Photogrammetry to support studies of wall stratigraphy and to allow a tentative test for reflection, analysis and comparison even remotely.

The second application is devoted to the use of modelling of ancient environments to support the promotion and dissemination of heritage to the wider public providing communicative models for the use in possible educational projects. The first study is focused on the masonry of the residential district, while the second on the mine inspected with the speleologists

\subsection{Hypothesis of basing vertical stratigraphic analysis on dense textured models}

The literature of the stratigraphy wall, with the cognitive and methodological contributions brought by Bianchi with the study of the masonry of the Rocca San Silvestro, are now based on the study of a small number of objective parameters concerning the masonry: the wall design, the ashlar dimensions, processing techniques and finishing, studying mortar and wall sections. (Bianchi, 1995)

These parameters of the archaeological study are certainly related to the physical and radiometric characteristics of the constructive elements that are described by image and surfaces analysis featured by the sub-centimetric resolution and metric accuracy offered by models based on LiDAR technology and integrated UAV photogrammetry.

In the present experience, a complete 3D textured mesh modelling has been achieved trying to integrate metric and radiometric information into vectorial graphical elaborations produced with the typical principles of architectural representation and aiming to meet the needs of reading archaeological data.

Contour lines, section profiles, high resolution orthophotos were then extracted from the multiscale model generating different scaled drawings, which retain the spatial reference (cartographic reference) of the overall model and are also produced at the scales of archaeological reading $(1: 20,1: 50,1: 100,1: 200,1$ : 500).

This approach provides the opportunity to consider the segmentation algorithms as a current and most effective method for transforming dense points or meshed models into usable products. The next figures try to present this study of model representation for major phases: figures 15 and 16 represents respectively the different walls constructive techniques and masonries typologies recognized by Bianchi that have been represented both in bidimensional vectorised drawings and by the segmentation of the mesh model. 

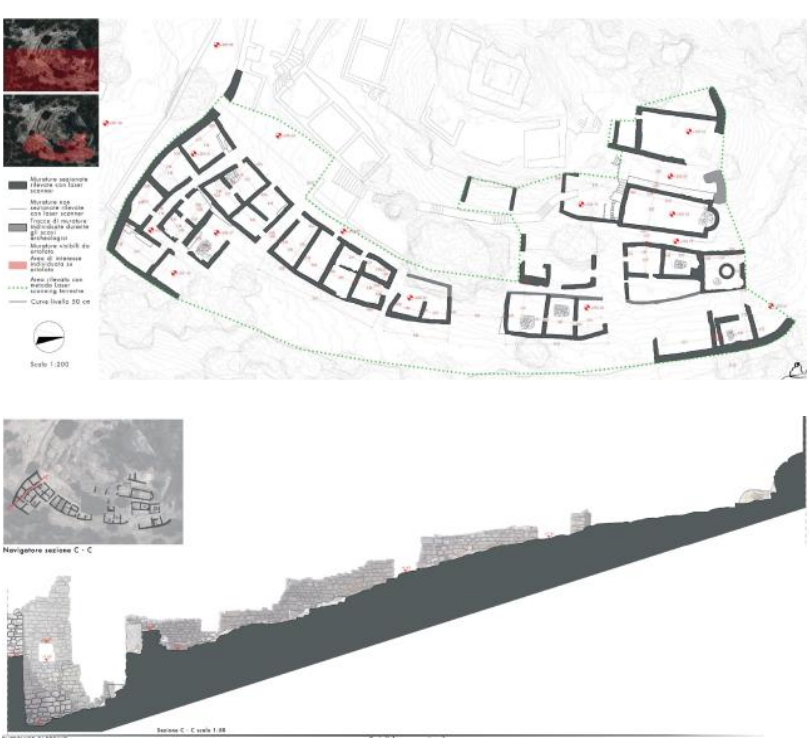

Figure 14. General 1:200 scale map of the residential district, showing the buildings' plans extracted from the TLS model and superimposed to the $50 \mathrm{~cm}$ equidistance contours lines generated from UAV Digital Surface model (DSM). (Villa, 2017)

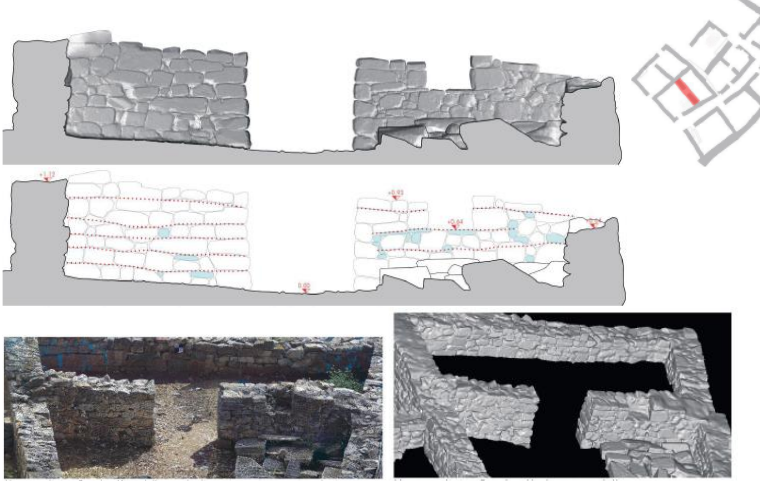

Figure 15 Masonry of type 3 a, b (Bianchi, 1995), (above) architectural vertical section (original scale 1:20) elaborated from the LiDAR and UAV integrated point clouds (centre) the technological analysis derived from Bianchi showing in red the position of lanks laying of masonry bricks and in blue are highlighted the wedge elements to regularise them.

\subsection{Modeling of the mine, an opportunity for communication}

The point cloud collected with the mobile laser mapping system has been processed and optimized by usual strategies for the elaboration of point clouds, very similar and therefore partially described in the TLS survey section. The great difference is Figure 16. The Bianchi typologies classification transposed in the 3D model of a portion of Rocca di San Silvestro.

obviously that the union of subsequent clouds is not here a heavy post-processing phase, but it is automatically obtained

Through some results of different processing phases, we can then present the most interesting aspects of these innovative data and related elaborations. Beyond the recall of the cloud density in relation to the displacement velocity, it is interesting to evaluate the overall accuracy of the cloud. Certainly, it must be recalled that while the system is able to work outdoor, it is thought and generally guarantees better accuracy in indoor environment, so a tunnel, although without geometric features that can function as a constraint, is a suitable space.
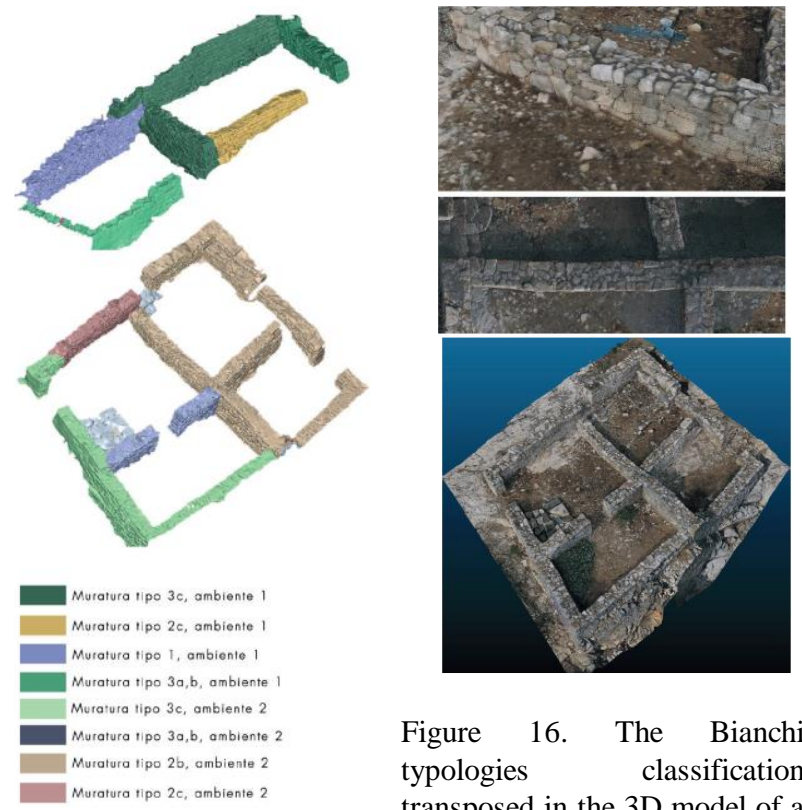

Figure 16. The Bianchi typologies classification transposed in the 3D model of a

portion of Rocca di San Silvestro.

Moreover, since a similar system was used precisely because of the inability or difficulty in measuring control points, two clouds have been segmented, corresponding respectively to the first round and return scanning of the mine, with the aim to estimate the accuracy. The result is figure 15 are really very appreciative: in about $75 \%$ of the surface the residuals are under $1 \mathrm{~cm}$.

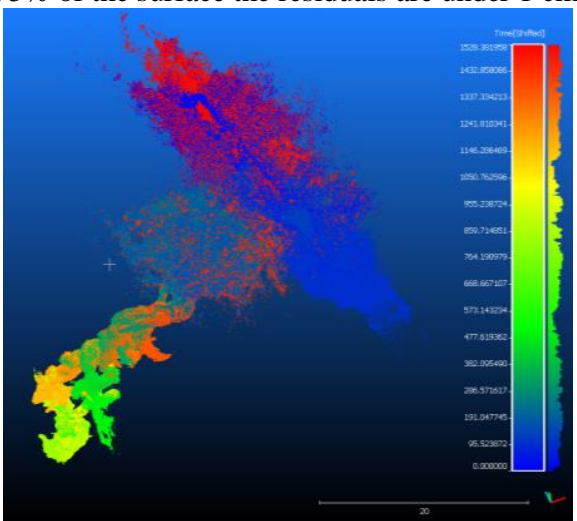

Figure 14. The colour ramp show the time sequence of cloud collection, and it is quite readable the low density of outdoor cloud portion, and very high density of indoor cloud (due to the slowness of on all fours moving forward).

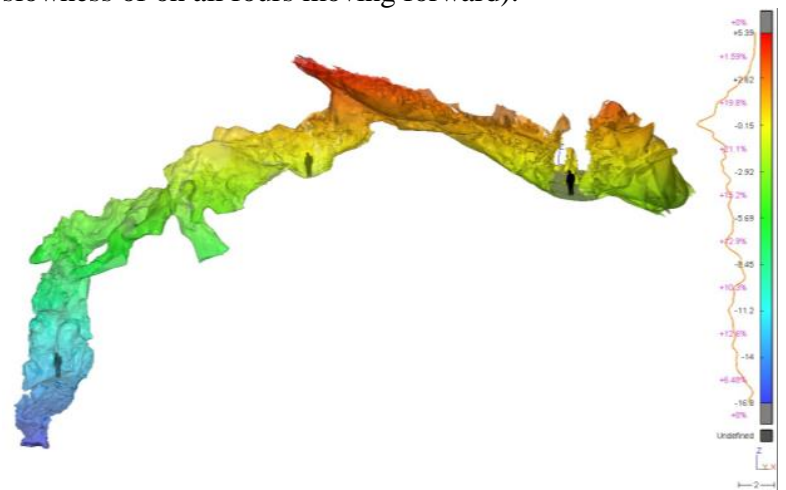

Figure 15. Comparison between two clouds corresponding to the first round and return scanning; residuals are very low for most of the surface. (under or near $1 \mathrm{~cm}$ ) 


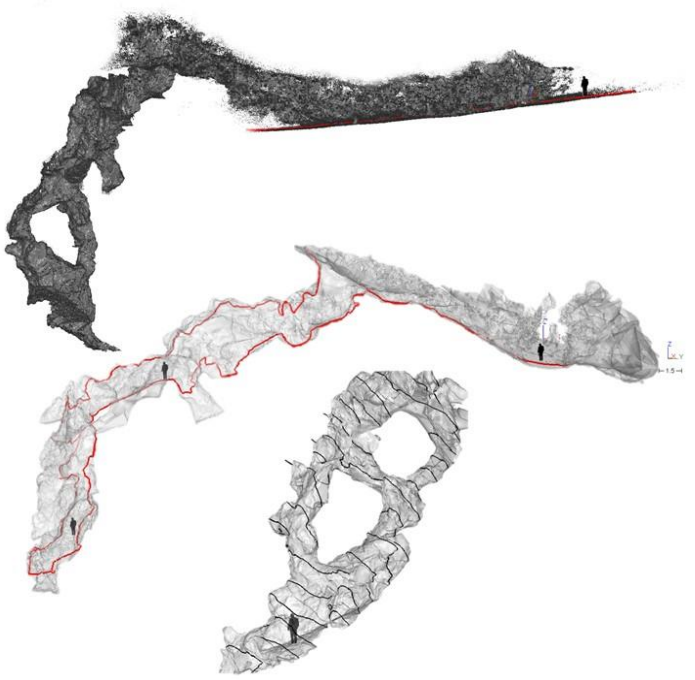

Figure 16. (Above) the rough cloud represented with $\mathrm{z}$ axis vertical; (centre) a continuous surface model showing the trajectory and human dimensions to understand the extension of internal spaces; (below) an example of extraction of automatical vertical section profiles.

\section{CONCLUSION AND FUTURE DEVELOPMENTS}

This project is undoubtedly characterized by multipurpose goals and contents: the collaboration with an institution that manages and preserves the archaeological and landscape heritage that has the role of stakeholders defining the qualification of documentation requirements, the training activity and ultimately the research and experimentation of new or recent technologies. All are particularly warm and of great relevance. It is perhaps worth recalling the prospects that need to be developed in the near future. In fact, special energies have to be devote to the development of platform integration, such as GIS and BIM, especially for the perspective of the need of navigating, managing and analysing 3D models represented at different scale in a single environment system. All this is bound to the need to harmonize the data with the standards that seek for interoperability and easy web access to information.

\section{ACKNOWLEDGEMENTS}

The authors would like to thank who allowed the project to be realize, firstly the director of the Val di Cornia Park S. Guideri, then the drone pilot P. Maschio, Andrea Lingua and students attending the site stage: M. Cazzola, A. Dervishi, F. Noardo, S. Perri, S. Rando, A. Spitalieri, G. Terramagna, C. Tosti. (https://www.facebook.com/Team-Direct-461829537253316/)

\section{REFERENCES}

Bianchi, G., 1995. L'analisi dell'evoluzione di un sapere tecnico per una rinnovata interpretazione dell'assetto abitativo e delle strutture edilizie del villaggio fortificato di Rocca San Silvestro. In: Acculturazione e mutamenti. (...) VI ciclo di lezioni sulla ricerca applicata in archeologia, pp. 361-396, Firenze.

Bianchi, G., 1996. Trasmissione dei saperi tecnici e analisi dei procedimenti costruttivi. In: Archeologia dell'Architettura, I, pp. 53-65.

Bianchi, G., 1997. Rocca S. Silvestro e Campiglia M. ma: storia parallela di due insediamenti toscani attraverso la lettura delle strutture murarie. In: 1st Congresso Nazionale di Archeologia Medievale (Pisa, 29-31 May 1997), Florencia, pp. 437-444.

Bosse M., Zlot R., 2009, Continuous 3D scan-matching with a spinning 2D laser, in IEEE Conference on Robotics and Automation

Bryan, P., Blake, B., and Bedford, J., 2013. Metric survey specifications for cultural heritage. English Heritage.

Colucci, E., 2017. Architettura e natura di paesaggi archeologici Analisi spaziali integrate in ambiente WEB-GIS per la conservazione e la comunicazione della memoria storica (...), Msc thesis, Politecnico di Torino, tutors, A. Spanò, F. Chiabrando, D. Brocchini.

Costamagna, E., Spanò, A., 2013. CityGML for Architectural Heritage. Developments in Multidimensional Spatial Data Models. Springer Berlin Heidelberg, pp. 219-237.

Chiabrando, F., Lingua, A. M., Maschio, P. F., and Teppati Losè, L., 2017. The influence of flight planning and camera orientation in UAVs photogrammetry. A test in the area of Rocca San Silvestro (LI), Tuscany. In: ISPRS Archives, 42, 163-170.

Sammartano, G.; Chiabrando, F.; Spanò, A., 2016. Historical buildings models and their handling via $3 \mathrm{~d}$ survey: from points clouds to user-oriented HBIM, In: ISPRS Archive, pp 633-640.

Francovich, R., Parenti, R., 1987, (edited by) Rocca San Silvestro e Campiglia. Prime indagini archeologiche. In: Quaderni del Dipartimento di Archeologia e Storia delle Arti. All'insegna del Giglio.

Francovich R., Wickham C. 1994, Uno scavo archeologico ed il problema dello sviluppo della signoria territoriale: Rocca San Silvestro e i rapporti di produzione minerari In: Archeologia Medievale XXI, pp. 7-30.

Guideri, S., 2008. Il Sistema dei Parchi della Val di Cornia e il Parco Archeominerario di San Silvestro (1996-2006). In: Bailly-Maitre, M C., Jourdanne-Annequin, C., Clermont-Joly, M., (edited by), Archéologie et paysage (...), Picard, Paris, pp. 187-195.

Kersten, T.P., Lindstaedt, M., 2012. Potential of Automatic 3D object reconstruction from multiple Images for applications in Architecture, International Journal of Heritage in the Digital Era, Multi Science Publishing, pp. 399-420

Murphy, M, McGovern, E, Pavia, S., 2009, Historic Building Information Modelling (HBIM), Structural Survey, vol. 27, no. 4, pp. $311-27$.

Noardo F., 2016. Spatial ontologies for Architectural Heritage, PhD thesis.

Ronzino, P., Niccolucci, F., Felicetti, A., Doerr, M. (2015). CRMBA a CRM extension for the documentation of standing buildings. International Journal on Digital Libraries, pp. 1-8.

Semplici, A., Brocchini, D. \& Guideri. S. (edited by), 2011. "Bianca e sfolgorante appare la Rocca...”. Guida al parco archeominerario di San Silvestro. Fotolito Toscana, Firenze.

Villa, A., 2017. Rocca medioevale di San Silvestro: modellazione 3D da rilievo UAV e laser scanning terrestre per lo studio e l'analisi del manufatto, Msc thesis, tutors, A. Spanò, F. Chiabrando. 